\title{
REPRESENTAÇÕES SOCIAIS DOCENTES ACERCA DOS CONCEITOS DE DEFICIÊNCIA E TECNOLOGIA ASSISTIVA
}

\author{
REPRESENTACIONES SOCIALES DE LOS DOCENTES SOBRE LOS CONCEPTOS \\ DE DISCAPACIDAD Y TECNOLOGÍA ASSISTENCIAL
}

\author{
A VIEW AT THE SOCIAL REPRESENTATIONS OF TEACHERS ABOUT THE \\ CONCEPTS OF DISABILITY AND ASSISTIVE TECHNOLOGIES
}

\author{
Tatiele Bolson MORO ${ }^{1}$ \\ Ygor CORREA ${ }^{2}$ \\ Valdinei MARCOLLA ${ }^{3}$ \\ Cristiane Backes WELTER ${ }^{4}$
}

RESUMO: Investigou-se, com base na Teoria das Representações Sociais (TRS), os tipos de deficiências declaradas pelos alunos do IFRS campus Caxias do Sul e os tipos de Tecnologia Assistiva (TA) disponibilizadas pela instituição. Esta pesquisa entrevistou oito professores e analisou suas narrativas, enquanto representações sociais, sobre Deficiência e TA. Além disso, 36 fichas de matrícula foram analisadas, revelando 16 tipos de deficiências, assim como 43 tipos de TA foram catalogadas na instituição. Então, a partir da TRS e da Análise de Conteúdo, constatou-se que os professores foram consensuais ao atribuir ao conceito de deficiência relação ao Modelo Médico e não ao Pós-Social. Pouca menção à utilização das TA foi constatada, porém os professores conheciam a relação dessas com as deficiências.

PALAVRAS-CHAVE: Teoria das representações sociais. Deficiência. Tecnologia assistiva. Professores.

RESUMEN: Se investigó, con base en la Teoría de las Representaciones Sociales (TRS), los tipos de deficiencias declaradas por los estudiantes IFRS en el campus de Caxias do Sul y los tipos de Tecnología Asistiva (AT) disponibles por la institución. Esta investigación entrevistó a ocho docentes y analizó sus narrativas, como representaciones sociales, sobre Discapacidad y TA. Además, se analizaron 36 formularios de inscripción, revelando 16 tipos de discapacidades. Así, en la institución se catalogaron 43 tipos de TA. Así, a partir de la TRS y Análisis de Contenido, se encontró que los docentes fueron consensuados en atribuir el concepto de discapacidad al Modelo Médico y no al Post-Social. Se hizo poca mención del uso de AT, pero los profesores eran conscientes de la relación entre estos y las deficiencias.

\footnotetext{
${ }^{1}$ Universidade de Caxias do Sul (UCS), Caxias do Sul - RS - Brasil. Doutoranda no Programa de PósGraduação em Educação. ORCID: https://orcid.org/0000-0002-3302-8953. E-mail: tati.bm@gmail.com

${ }^{2}$ Universidade de Caxias do Sul (UCS), Caxias do Sul - RS - Brasil. Professor no curso de Graduação em Pedagogia. Doutorado em Informática na Educação (UFRGS). ORCID: https://orcid.org/0000-0002-3526-9195. E-mail: correaygorprof@gmail.com

${ }^{3}$ Instituto Federal Catarinense (IFC), Videira - SC - Brasil. Professor EBTT. Doutorado em Educação (UFPEL). ORCID: https://orcid.org/0000-0002-9057-9399. E-mail: valdinei.marcolla@gmail.com

${ }^{4}$ Universidade de Caxias do Sul (UCS), Caxias do Sul - RS - Brasil. Coordenadora e Professora do Curso de Pedagogia. Doutorado em Educação (UNISINOS). ORCID: https://orcid.org/0000-0002-8476-2939. E-mail: cbwelter@ucs.br
}

RIAEE - Revista Ibero-Americana de Estudos em Educação, Araraquara, v. 16, n. esp. 4, p. 3049-3071, dez. 2021. e-ISSN: 1982-5587 
PALABRAS CLAVE: Teoría de las representaciones sociales. Deficiencia. Tecnología de assistência. Maestros.

ABSTRACT: Based on Social Representation Theory (SRT), we investigated the types of disabilities declared by IFRS-Caxias do Sul students and the available types of Assistive Technology (AT). This research interviewed eight teachers and analyzed their narratives, as social representations, about Disability and AT. In addition, 36 enrollment forms were analyzed, revealing 16 types of disabilities. As well as 43 types of AT were cataloged at the institution. Then, based on SRT and Content Analysis, it was found that teachers were consensual when attributing the concept of disability to the Medical and non-Post-Social Model. Little mention was made of the use of AT, but teachers were aware of the relationship between them and the disabilities.

KEYWORDS: Theory of social representation. Disability. Assistive technology. Teachers.

\section{Introdução}

Este estudo investiga quais são as principais deficiências declaradas pelos alunos do Instituto Federal de Ciência, Educação e Tecnologia do Rio Grande do Sul (IFRS) do campus Caxias do Sul e os tipos de Tecnologia Assistiva (TA) (CAT, 2009) disponibilizadas pelo Núcleo de Atendimento às Pessoas com Necessidades Educacionais Específicas (NAPNE) do IFRS. Ao adotar-se o aporte teórico-epistemológico da Teoria das Representações Sociais (TRS) tem-se por objetivo analisar e compreender se as representações sociais (CAMPOS, 2017; JODELET, 2002) construídas pelos professores vão ao ou de encontro ao que é postulado pela literatura acerca dos Modelos de Deficiência (DINIZ; BARBOSA; SANTOS, 2009; MARTÍN; CASTILLO, 2010; FERREIRA, 2011; BISOL; PEGORINI; VALENTINI, 2017) e das concepções sobre TA voltadas às Pessoas com Deficiências (PcDs) (BRASIL, $2000 ; 2015)$.

O referencial teórico apresenta uma breve síntese dos Modelos de Deficiência, percorrendo o Modelo Caritativo, o Modelo Médico, o Modelo Social, até o atual Modelo Pós-Social (MARTÍN; CASTILLO, 2010; FERREIRA, 2011; DINIZ; BARBOSA; SANTOS, 2009; BISOL; PEGORINI; VALENTINI, 2017). Após, discorre-se sobre o conceito de Tecnologia Assistiva (TA) e o modo como essas estão classificadas, a fim auxiliar e promover a autonomia e o desenvolvimento integral das PcDs, com vista à inserção dessas em uma sociedade com mais equidade social, política, cultural e educacional (BERSCH, 2017; WARSCHAUER, 2006). Neste estudo, assume-se, a partir da perspectiva vigotskiana (VIGOTSKI, 1991), que as TA, quando coerentemente utilizadas, podem auxiliar nos 
processos de mediação, para fins de aprendizagem ou consolidação de um determinado conhecimento preexistente, potencializando o desenvolvimento humano. Muito embora não adentremos a temática, essa é a tomada de posição epistêmica dos autores deste artigo.

Em seguida, caracteriza-se o IFRS quanto ao seu Projeto Pedagógico Institucional (PPI) direcionado ao atendimento de alunos com Necessidade Educacionais Específicas (NEEs) e, por fim, procura-se apresentar o IFRS campus Caxias do Sul enquanto lócus de pesquisa. Esta é uma pesquisa qualitativa e exploratória (SAMPIERI; COLLADO; LUCIO, 2013), em que, em uma primeira etapa, analisou-se as fichas cadastrais de matrícula de 36 alunos com diferentes deficiências, durante o período de 2015 a 2019, no âmbito de cursos da Educação Básica (nível técnico) e da Educação Superior (nível graduação). Os dados foram coletados junto ao NAPNE e à Coordenadoria de Registros Escolares do IFRS campus Caxias do Sul. Quanto aos recursos de TA disponibilizados pela instituição, esses foram catalogados a partir de visitas guiadas.

Em uma segunda etapa, foram entrevistados 08 professores do IFRS campus Caxias do Sul, que atuam no ensino de alunos com NEEs, por meio de um questionário semiestruturado, com o objetivo de coletar, analisar e compreender nas narrativas docentes, enquanto representações sociais acerca de conceitos como Deficiência e TA, quando de suas práticas pedagógicas. As narrativas dos professores foram analisadas com base na TRS e na técnica de Análise de Conteúdo (BARDIN, 2011), o que permitiu, como pode ser visto neste artigo, a apresentação de fragmentos discursivos na seção de análise que evidenciam as concepções acerca do tema investigado.

\section{Modelos de deficiência}

Historicamente, sempre existiram pessoas acometidas por algum tipo de deficiência, cujas causas e consequências, muitas vezes pouco investigadas, levaram-nas à exclusão social (DINIZ; BARBOSA; SANTOS 2009; FERREIRA, 2011). Em geral, os deficientes não eram estimulados ou inseridos na sociedade, haja vista a compreensão social de que não poderiam atuar de forma ativa e produtiva para o desenvolvimento econômico, político e cultural da sociedade em que viviam. Segundo Diniz, Barbosa e Santos (2009), o conceito de deficiência profere que este "não se resume ao catálogo de doenças e lesões de uma perícia biomédica do corpo é um conceito que denuncia a relação de desigualdade imposta por ambientes com barreiras a um corpo com impedimentos" (DINIZ; BARBOSA; SANTOS 2009, p. 65). 
A premissa mencionada está, sem dúvida, contemplada por Modelos de Deficiência (MARTÍN; CASTILLO, 2010; FERREIRA, 2011) que, socioculturalmente, em diferentes períodos históricos, atribuíram postulações e rótulos que colocam o deficiente como um doente, ou que precisa da piedade de outros, que tenha a deficiência por um castigo divino, que coloca a sociedade como problema para a inclusão $\mathrm{PcD}$, ou ainda que toma a deficiência como um aspecto constitutivo do indivíduo e não como condição final e limitadora para sua participação em sociedade. Cabe levar em consideração que, em se tratando da referência a uma comunidade ou parcela da sociedade, os dados da cartilha do Censo de 2010 (BRASIL, 2010), elaborada pelo Instituto Brasileiro de Geografia e Estatística (IBGE) ${ }^{5}$, informam que existem 45.606 .048 brasileiros com algum tipo de deficiência, ou seja, 23,9\% da população. Ainda nesse levantamento, constatou-se que 18,6\% dos brasileiros têm deficiência visual, 7\% deficiência motora, 5,1\% deficiência auditiva e 1,4\% deficiência intelectual. Esses percentuais deixam evidente a latente demanda por leis e documentos nacionais ${ }^{6}$ que assegurem e fiscalizem os direitos das PcDs no Brasil.

De modo a não perder de vista a tônica em pauta, inferimos que, com base na literatura da área, quatro Modelos de Deficiência ajudam-nos a compreender o que foi mencionado, isso porque colocam luz não apenas sob o conceito, mas por focalizarem a transição de uma concepção de deficiência para outra em um continuum diacrônico. Frente ao que foi dito, apresenta-se, brevemente, os Modelos de Deficiência, a saber: o primeiro, intitulado(a) Modelo Caritativo (até século XVIII), em que a pessoa era considerada diferente da normalidade, sendo incapaz, digna de ajuda e caridade (MARTÍN; CASTILLO, 2010; FERREIRA, 2011). Já o (b) Modelo Médico (entre pós-guerras e 1960) baseia-se na medicina moderna que trata a deficiência como uma patologia e tenta a reabilitação clínica (DINIZ; BARBOSA; SANTOS, 2009), enquanto que no (c) Modelo Social (de 1960 a 1980) volta-se para a mobilização política, a fim de reivindicar os direitos à inclusão, à integração da PcD na sociedade e à aceitação das diferenças, de modo a compreender que as limitações estão na sociedade e não exatamente no sujeito (MARTÍN; CASTILLO, 2010; FERREIRA, 2011). Por fim, o quarto, é o (d) Modelo Pós-Social (a partir de 1980), que concebe que o indivíduo com

${ }^{5}$ O Relatório do Censo de 2010 foi o último a ser publicado pelo governo Federal. No entanto, tem-se em caráter extraoficial uma apresentação em PowerPoint, publicada na página da Câmara dos Deputados, na qual se pode ter acesso aos dados que possivelmente comporão o Censo de 2020. Ao passo que estes não são dados oficialmente validados em Diário Oficial no território brasileiro, infere-se que a adesão de tais informações pode enviesar as informações oficiais contidas no Censo de 2010. Todavia, o referido documento pode evidenciar uma significativa diminuição do número de pessoas com algum tipo de deficiência, de $23,9 \%$ da população para $6,7 \%$ da população.

${ }^{6}$ Considerando o ano atual, 2021, tem-se consciência de que esse número deva ser maior pelas consequências da pandemia COVID-19, que provocaram um aumento da incidência de diferentes tipos de deficiência no país.

RIAEE - Revista Ibero-Americana de Estudos em Educação, Araraquara, v. 16, n. esp. 4, p. 3049-3071, dez. 2021. e-ISSN: 1982-5587 
PcD tem demandas e capacidades para além de sua deficiência e está inserido em uma sociedade com barreiras - este modelo ainda está em construção (DINIZ; BARBOSA; SANTOS, 2009; BISOL; PEGORINI; VALENTINI, 2017). Sobre o Modelo Pós-Social, pode-se dizer que este visa à construção de novas práticas sociais, que auxiliem na inclusão de PcDs, e contextualiza que uma PcD não é apenas um corpo com impedimentos, mas uma pessoa com impedimentos e que vive em um meio com barreiras, mantendo a reconceitualização da deficiência. Salienta-se, contudo, que contemporaneamente,] tem-se uma compreensão de deficiência ainda imbuída, principalmente, dos modelos caritativo e médico, por mais que isso possa causar estranhamento diante dos avanços científicos que se tem registro. Cabe ressaltar ainda, que, este estudo apoia-se no Modelo Pós-Social, enquanto posicionamento teórico-epistemológico, basilar na construção de nossas lentes científicas e em consonância com o status quo da temática aqui investigada.

$\mathrm{Na}$ medida em que as políticas públicas identifica(ra)m e reconhece(ra)m (BRASIL, 2004 2015, 2016,) a existência de PcDs (BRASIL, 2000), foi (é) preciso legislar a favor dessas, de modo a inseri-las de forma não apenas integrativa, mas equânime, ou seja, com vista a suprir as especificidades de cada deficiência, visando a tornar possível a inserção social dessas, seja em contexto de lazer, de trabalho ou educacional. Desta forma, é apresentado na próxima seção o contexto da Tecnologia Assistiva.

\section{Tecnologia Assistiva}

No que concerne, em especial, ao âmbito educacional, novas práticas têm surgido (BERSCH, 2017), em todos os níveis educacionais, Educação Básica e Superior, para que a inclusão de alunos com deficiência(s) ocorra e se configure, não como um mero cumprimento de leis e do Projeto Pedagógico Institucional ${ }^{7}$ (PPI), mas, principalmente, como forma de conscientização e de mudança das representações sociais, por parte da sociedade, quanto àqueles que têm uma deficiência. No cenário da(s) deficiência(s) e da Inclusão (CARVALHO, 2016), percebe-se recentemente, no Brasil, o surgimento do conceito de Tecnologia Assistiva (TA), que é denominado por Bersch (2017), Cook e Hussey (1995) e Comitê de Ajudas Técnicas (CAT, 2009) como o uso de recursos e serviços que auxiliam a pessoa com deficiência $(\mathrm{PcD})$, de forma a promover sua autonomia e independência. No

7 Projeto Pedagógico Institucional do IFRS elaborado em 2010 e publicado em 2012. Disponível em: https://rb.gy/2ktof9. Acesso em: 03 mar. 2020

RIAEE - Revista Ibero-Americana de Estudos em Educação, Araraquara, v. 16, n. esp. 4, p. 3049-3071, dez. 2021. e-ISSN: 1982-5587 
Brasil, o conceito de TA é definido pelo CAT, que trata das TA ou das Ajudas Técnicas. O CAT definiu o conceito de TA em 2006 e voltou a atualizá-lo em 2009 informando que:

[...] engloba produtos, recursos, metodologias, estratégias, práticas e serviços que objetivam promover a funcionalidade, relacionada à atividade $\mathrm{e}$ participação, de pessoas com deficiência, incapacidades ou mobilidade reduzida, visando sua autonomia, independência, qualidade de vida e inclusão social (CAT, 2009, p. 9).

Esse conceito abordado pelo CAT também foi registrado na Lei $n^{0} 10.098 / 2000$, que estabelece normas e critérios para a promoção da acessibilidade das PcDs ou com mobilidade reduzida, e é retomado também pela Lei 13.146/2015, que trata sobre a Inclusão da Pessoa com Deficiência (Estatuto da Pessoa com Deficiência) (BRASIL, 2000; 2015). Esses documentos são corroborados por Bersch (2017), que aborda o objetivo da TA, que é proporcionar à $\mathrm{PcD}$ “[...] maior independência, qualidade de vida e inclusão social, através da ampliação de sua comunicação, mobilidade, controle de seu ambiente, habilidades de seu aprendizado e trabalho" (BERSCH, 2017, p. 2). O conceito de TA também é assumido por Cook e Hussey (1995) e CAT (2009) como uma forma de reduzir as limitações das PcDs.

Assim, cabe ressaltar que o conceito de TA, publicado pelo CAT em 2009, não contempla a presença e a utilização da TA sob o escopo de recursos digitais (CAT, 2009), que estão massivamente presentes na sociedade, supostamente, hiperconectada (CASTELLS, 1999). Tem-se, portanto, um hiato de onze anos desde a publicação realizada pelo CAT (2009), o que torna inquestionável não considerar o uso da TA em formato digital, sejam elas dispositivos móveis ou softwares em geral. Segundo Warschauer (2006), as ações dos indivíduos podem ser facilitadas com o uso de ferramentas tais como TA, podendo assim, ao serem utilizadas, alterar a sequência e a estrutura das funções mentais de seus usuários, podendo potencializar os processos de ensino e de aprendizagem.

As TA podem ser classificadas em serviços e em recursos (BERSCH, 2017). Os serviços auxiliam a estudante com NEE na seleção, aquisição ou uso de TA ou até mesmo de, por exemplo, interpretação realizada por intérpretes de língua brasileira de sinais (Libras). Os recursos são equipamentos, componentes, produtos ou sistemas que são usados para aumentar ou melhorar as capacidades funcionais dos estudantes com NEE. Os recursos são subdivididos em: (a) Auxílios para a vida diária e prática; (b) Comunicação Aumentativa e Alternativa (CAA); (c) Recursos de Acessibilidade ao computador; (d) Sistemas de Controle de Ambiente; (e) Projetos Arquitetônicos para Acessibilidade; (f) Órteses e Próteses; (g) Adequação Postural; (h) Auxílios de Mobilidade; (i) Auxílios para Cegos ou com Visão 
Subnormal; (j) Auxílios para pessoas com surdez ou com déficit auditivo; (1) Adaptações em veículos; e (m) Esportes e lazer (BERSCH, 2017). Os recursos, que não sejam os de acessibilidade ao computador (softwares), são nomeados como recursos de Auxílio, pois se configuram como TA, que se voltam a promover a acessibilidade e a facilitar as ações diárias, como, por exemplo, a lupa, o engrossador de lápis, a prancha braile ou o rotulador braile, sobre outras finalidades de ajuda aos estudantes com NEEs.

Dessa forma, é importante considerar as especificidades de cada pessoa com deficiência quando da escolha de uma TA, pois existem diversos tipos e graus de comprometimento que requerem atenção sobre as necessidades de cada sujeito (CAT, 2009; BERSCH, 2017). Assim, partir da ótica vigotskiana, uma TA pode auxiliar na mediação (internalização de atividades e comportamentos, incluindo ferramenta e signos [VIGOTSKI, 1991]) das relações de sujeitos com algum tipo de deficiência.

O uso da TA pode auxiliar nos processos de desenvolvimento humano, de modo que ocorra assim a movimentação dos saberes dos indivíduos de uma zona de desenvolvimento para outra (VIGOTSKI, 1991). Este "movimentar-se" de uma zona para outra compreende o desenvolvimento das capacidades cognitivas por meio de interações, o que pode permitir a aprendizagem de conhecimentos ou aperfeiçoamentos de processos existentes. Estudos anteriores, envolvendo sujeitos com deficiência física (FERRADA; SANTAROSA, 2009, BISOL et al., 2018), sujeitos surdos (CORRÊA et al., 2014; CORRÊA; GOMES; RIBEIRO, 2018), sujeitos cegos ou com limitação visual (SONZA; SANTAROSA, 2003; BARWALDT; SANTAROSA; PASSERINO, 2008), entre outros (SONZA et al., 2013; SONZA; SALTON; STRAPAZZON, 2015), têm destacado o potencial do uso da TA como mediadoras da construção do conhecimento, da subjetivação e da autonomia.

\section{Teoria das Representações Sociais}

No que concerne à relação da Teoria das Representações Sociais (TRS) com a área da Educação no Brasil, em especial, voltada à Educação Inclusiva, infere-se, de acordo com as postulações de Campos (2017, p. 776), que a TRS "tem aportado uma contribuição significativa, com destaque, particularmente, nas áreas do trabalho docente e da educação inclusiva". Ainda segundo Campos (2017, p. 776), a TRS tem sido adotada quanto a aspectos como "a focalização das políticas públicas no professor, sua ação, seu papel na escola, sua formação e os aspectos simbólicos ou culturais que o envolvem como agente [...]". 
A adoção pela TRS e seu delineamento teórico-epistemológico se deve ao fato de que o conceito de Representações Sociais (RS) está compreendido como "[...] uma forma de conhecimento socialmente elaborado e compartilhado, com um objetivo prático, e que contribui para a construção de uma realidade comum a um conjunto social" (JODELET, 2002, p. 22). Neste sentido, considera-se que as representações sociais de docentes, atuantes em um contexto educacional (IFRS campus Caxias do Sul, no caso desta pesquisa) voltado à deficiência, à inclusão e ao uso de TA podem possibilitar a compreensão de saberes consolidados "pelas inter-relações eu[docente]/outro[aluno/deficiência]/objeto-mundo[TA]"8, os quais são construídos pelos sujeitos de modo dialógico (interação em sala de aula), conforme Jovchelovitch (2008, p. 21) e Mazzotti (2002).

As representações sociais, por sua vez, são elementos simbólicos, socialmente construídos e manifestados pelos sujeitos pela linguagem (oral, escrita, sinais, entre outros), por meio dos quais se pode identificar crenças, sentimentos (conscientes e inconscientes), valores socioculturais, na forma de conhecimentos que são transmitidos entre indivíduos em situações culturais. Assim, os sujeitos inseridos nas situações culturais são produtos e produtores de uma determinada realidade. De acordo com Jodelet (2001, p. 21), as representações sociais comportam em si "a aparência de um saber", que revela algo em relação ao estado de uma determinada realidade. Ainda neste tocante, Giust-Desprairies (2005, p. 174) afirma que:

As representações sociais dizem igualmente respeito à construção de uma realidade colectiva própria a um grupo social determinado para o qual ela se constitui como instrumento de orientação da percepção das situações e de elaboração de resposta. Por fim, porque elas se formam a partir das interacções, as representações dizem respeito às condutas colectivas, às comunicações sociais, e constituem uma legitimação do senso comum.

Mazzotti (2011) infere que o "uso das técnicas retóricas como meios para analisar discursos permite maior grau de controle das inferências dos pesquisadores" em se tratando de um protocolo de análise baseado na TRS. Quanto à atuação do profissional da Educação, Vala (2004) infere que os docentes não apenas recebem e processam conteúdos informacionais (produtos do meio), mas, também são responsáveis pela elaboração de significados e que eles, além disso, teorizam acerca da realidade social que se encontram (produtores). Sousa (2002), por sua vez, ao referir-se à adoção da TRS para a compreensão de aspectos relacionados à Educação e aos educadores, julga-a como capaz de abarcar dimensões micro e macrossociais,

${ }^{8}$ Grifos dos pesquisadores.

RIAEE - Revista Ibero-Americana de Estudos em Educação, Araraquara, v. 16, n. esp. 4, p. 3049-3071, dez. 2021. e-ISSN: 1982-5587 
que envolvem os atores envolvidos quando da construção de representações sociais, enquanto senso comum (MOSCOVICI, 1978), dotado de caráter teórico-prático das experiências socioculturais. Infere-se que a TRS, posto seu caráter psicossocial, pode possibilitar a identificação de processos simbólicos manifestados, consciente ou inconsciente, acerca dos diversos aspectos presentes na Educação Inclusiva. Portanto, a TRS pode auxiliar na compreensão das representações sociais construídas pelos docentes da instituição enquanto grupo, posto que essa pode não ser a mesma descrita e prescrita na legislação e nos usos previstos.

Dito de outro modo, pode haver aí uma interpretação e utilização que não aquelas normatizadas pelo sistema educacional, mas, sim, localmente elaboradas, sob uma concepção validada pelos pares dentro do âmbito institucional. Neste sentido, julga-se relevante mapear as representações sociais dos docentes (construções mentais e suas atividades simbólicas) e não as tomar como de total homogeneização, dentro de um sistema social supostamente uno. Neste horizonte, faz-se relevante, enquanto objeto representacional, analisar como os docentes pesquisados neste estudo compreendem suas representações sociais para os conceitos de deficiência e de TA no ambiente educacional em que estão inseridos. Na próxima seção discorre-se sobre o contexto educacional em que ocorreu a presente pesquisa.

\section{Instituto Federal Do Rio Grande do Sul - campus Caxias do Sul}

O Instituto Federal de Educação, Ciência e Tecnologia do Rio Grande do Sul (IFRS), conforme seu Projeto Pedagógico Institucional, é uma instituição federal de ensino público e gratuito, sendo dividido em vários campi para promover a educação profíssional e tecnológica, com o intuito de estimular o desenvolvimento das regiões, e tem como premissa: "[...] o desenvolvimento integral do cidadão, a equidade; a competitividade econômica - vista de forma humanizada num processo de globalização - e a geração de novas tecnologias" (IFRS, 2012).

O IFRS enquanto rede possui 17 campi, Bento Gonçalves, Canoas, Caxias do Sul, Erechim, Farroupilha, Feliz, Ibirubá, Osório, Porto Alegre, Restinga (Porto Alegre), Rio Grande e Sertão e, em processo de implantação: Alvorada, Rolante, Vacaria, Veranópolis e Viamão. A Reitoria é sediada em Bento Gonçalves. Todos os campi atendem PcDs. O IFRS campus Caxias do Sul oferta educação profissional e tecnológica em diferentes níveis e modalidades de ensino (médio, técnico, superior e pós-graduação), articulando a Educação Básica e a Educação Tecnológica à Educação Superior. Sendo assim, a configuração da 
Educação Profissional é estruturada da seguinte forma: Subsequente, Concomitante e Integrado ao Ensino Médio, ao Ensino Superior e à Pós-Graduação. De acordo com o PPI, o objetivo da formação é projetar uma sociedade baseada em relações socialmente equânimes, na qual seja remetida pela democracia ao conceito de cidadania, pois isso consiste na possibilidade de todas as pessoas terem acesso à educação, à cultura, ao trabalho, à qualidade de vida etc., de modo a promover a transformação humana na direção do seu desenvolvimento pleno (IFRS, 2012).

O IFRS campus Caxias do Sul está situado na Serra Gaúcha, a 130 quilômetros da capital, Porto Alegre. O campus contabiliza um total de 1466 alunos, dentre as modalidades de ensino ofertadas; 671 alunos do ensino médio integrado, 90 alunos no ensino médio integrado - PROEJA, 87 alunos no ensino médio subsequente e 618 alunos do ensino superior. O IFRS campus Caxias do Sul promove cursos como: a) Técnico em Fabricação Mecânica (integrado), b) Técnico em Plásticos (integrado e subsequente), c) Técnico em Química (integrado), d) Técnico em Administração (integrado na modalidade educação de jovens e adultos - PROEJA), e) Superior em Engenharia de Produção, f) Engenharia Metalúrgica, g) Licenciatura em Matemática, h) Tecnologia em Processos Gerenciais, i) Tecnologia em Processos Metalúrgicos, j) Pós-Graduação em Docência em Educação Básica e Profissional e k) Mestrado Profissional em Tecnologia e Engenharia de Materiais. Na próxima seção apresenta-se a metodologia de pesquisa do estudo realizado.

\section{Metodologia}

Esta é uma pesquisa qualitativa e exploratória (SAMPIERI; COLLADO; LUCIO, 2013), a qual está dividido em duas etapas.

$\mathrm{Na}$ primeira etapa, verificou-se quais seriam os tipos de deficiências dos alunos do IFRS campus Caxias do Sul e quais recursos de TA eram disponibilizados na instituição. As informações foram coletadas junto à Coordenadoria de Registros Escolares e ao Núcleo de Atendimento às Pessoas com Necessidades Educacionais Específicas (NAPNE). Os dados foram obtidos por meio de 36 fichas cadastrais dos alunos (identificações anonimizadas pela instituição), que estão ou estiveram matriculados no campus no período de 2015 a 2019, o que permitiu mapear e classificar o(s): (a) ano de ingresso no IFRS campus Caxias do Sul, (b) tipos de deficiências dos alunos e (c) nível educacional.

Em relação às TA, essas foram catalogadas a partir de duas visitas guiadas ao IFRScampus Caxias do Sul, enquanto exploração do campo de pesquisa, in loco, as quais contaram 
com o acompanhamento de uma Técnica em Atendimento Educacional Especializado (AEE). Após a visita e para fins de registro das TA identificadas, os recursos de auxílio e de software foram catalogados em planilha. O levantamento realizado na primeira etapa desta pesquisa possibilitou a elaboração de dois quadros apresentadas na seção de Análise de Dados.

Na segunda etapa, analisou-se com base na Teoria das Representações Sociais (TRS) (CAMPOS, 2017; JODELET, 2001; 2002; JOVCHELOVITCH, 2008; MOSCOVICI, 1978), em diálogo com a literatura sobre Deficiência (DINIZ; BARBOSA; SANTOS, 2009; MARTÍN; CASTILLO, 2010; FERREIRA, 2011; BISOL; PEGORINI; VALENTINI, 2017) e TA (BERSCH, 2017; CAT, 2009; COOK; HUSSEY, 1995), as respostas informadas por oito professores do IFRS campus Caxias do Sul, quando da entrevista por questionário online, composto por 21 questões semiestruturadas. O questionário foi dividido em: caracterização dos sujeitos, seguida por 04 eixos temáticos: (a) Formação Docente; (b) Trabalho Docente; (c) Recursos de TA; e (d) Atendimento a alunos com NEEs. Esse questionário continha 02 questões de múltipla escolha e 19 questões dissertativas; após o retorno do questionário as respostas foram reunidas em função dos eixos temáticos para que fossem realizadas as análises.

Os docentes entrevistados atuam no Ensino Médio Integrado, Ensino Médio Integrado PROEJA, Ensino Subsequente e Ensino Superior, ministrando aulas para estudantes com NEEs. A faixa-etária dos professores oscilou entre 33 e 43 anos, sendo o grupo composto por 04 docentes do gênero feminino e 04 docentes do gênero masculino. A formação acadêmica inicial de todos era de ensino superior.

A escolha envolvendo os entrevistados em questão deu-se por "conveniência e acessibilidade aos entrevistados" (SAMPIERI; COLLADO; LUCIO, 2013, p. 409), de forma anonimizada e intermediada junto ao NAPNE. Já quanto ao reduzido número de entrevistados, tendo em vista se tratar de uma análise de narrativas pautada na TRS e na Análise de Conteúdo (BARDIN, 2011), que visa à identificação de representações sociais de docentes de uma instituição específica, considerou-se, segundo Cresswell (2013, p. 223), que os pesquisadores procuraram identificar "tantos incidentes, eventos ou atividades quanto seja possível para apoiarem as categorias", e nesta busca, ao constataram "que as categorias estão "saturadas"”, portanto, sem ocasionar informações distintas às já identificadas. Para Cresswell (2013, p. 134), “o ponto importante é descrever o significado do fenômeno para um pequeno número de indivíduos que o experimentaram". Uma vez que se identificou fragmentos discursivos em conformidade com a narrativa de três docentes entrevistados, inferiu-se o número como suficiente, todavia, na tentativa de validar a conformidade discursiva dos 
entrevistados, optou-se por considerar a participação de mais cinco (5) indivíduos. Sampieri, Collado e Lucio (2013) depreendem que o número de participantes na pesquisa qualitativa está diretamente associado ao entendimento do que se investiga acerca do fenômeno sob análise, aspecto que tende a não fixar um número ideal e determinado de participantes.

$\mathrm{O}$ conceito de TA foi abordado por meio de perguntas que possibilitassem compreender as crenças, valores e signos conferidos pelos professores aos objetos de representações sociais. A Análise de Conteúdo (AC) tem sido adotada em pesquisas qualitativas nas áreas das Ciências Sociais, Psicologia e Educação. Segundo Bardin (2011, p. 38), a AC é composta "por procedimentos sistemáticos e objetivos de descrição do conteúdo das mensagens, indicadores (quantitativos ou não)", os quais permitem extrair conhecimentos quanto ao contexto/cenário de produção/recepção em que os indivíduos emitem determinada informação (verbal ou não verbal). Uma vez que a AC comporta em si três etapas, a saber, (a) pré-análise, (b) exploração do material e (c) tratamento dos resultados, optou-se, metodologicamente, por seguir os critérios para fins de compreensão do fenômeno investigado. Assim, com base na AC, conduziu-se a leitura flutuante (BARDIN, 2011) das respostas dissertativas dos questionários semiestruturados, a fim de compreender, identificar, extrair e apresentar o agrupamento de narrativas e de fragmentos discursivos enquanto unidades de sentido, neste estudo na forma de 04 eixos temáticos. Para apresentar as narrativas, optou-se por nomear os sujeitos de pesquisa com a inicial $(\mathrm{P})$, referente ao Participante, e um número arábico, por exemplo, (P1), com o intuito de preservar o total anonimato dos participantes. Na próxima seção, apresenta-se a análise de dados do estudo.

\section{Análise de dados}

Nesta seção, apresenta-se, isoladamente, os achados de cada etapa de pesquisa deste estudo, sendo elas: (a) a primeira, focada nos alunos com deficiência e TA presentes na instituição pesquisada e, (b) a segunda, voltada para a entrevista com professores acerca dos alunos com deficiências, formação com TA e uso dessas para fins educacionais; por fim, faremos considerações entre a relação entre as duas etapas.

$\mathrm{Na}$ primeira etapa, a análise das 36 fichas cadastrais anonimizadas de alunos que tiveram ingresso no IFRS campus Caxias do Sul enquanto PcD(s), durante o período de 2015 a 2019. Esses alunos apresentavam faixa-etária entre 14 entre 35 anos de idade, sendo 29 do gênero masculino e 07 do gênero feminino. A tabulação dos dados das fichas cadastrais possibilitou a elaboração do Quadro 1, na qual: (a) ano de ingresso; (b) tipo de deficiência, (c) 
número de alunos e (d) nível educacional foram mapeados. Portanto, no Quadro 1 é possível visualizar um panorama das deficiências informadas pelos alunos.

Quadro 1 - Levantamento dos Tipos de Deficiências

\begin{tabular}{|c|c|c|c|}
\hline ANO & DEFICIÊNCIA & $\begin{array}{c}\mathbf{N}^{\mathbf{o}} \\
\text { ALUNOS }\end{array}$ & $\begin{array}{c}\text { NÍVEL } \\
\text { EDUCACIONAL }\end{array}$ \\
\hline \multirow{3}{*}{2015} & Transtorno do Déficit de Atenção com Hiperatividade & 5 & Ensino Técnico \\
\hline & Baixa Visão & 1 & Ensino Técnico \\
\hline & Déficit de Atenção & 1 & Ensino Técnico \\
\hline \multirow{4}{*}{2016} & Neuropatia de Charcot Marie Tooth (Membros inferiores) & 1 & Ensino Técnico \\
\hline & Baixa visão & 1 & Ensino Técnico \\
\hline & Síndrome de Down & 1 & Ensino Técnico \\
\hline & Paralisia Cerebral & 1 & Ensino Superior \\
\hline \multirow{7}{*}{2017} & Redução do Equilíbrio Corpóreo & 1 & Ensino Superior \\
\hline & Déficit Neurológico & 1 & Ensino Superior \\
\hline & Surdez & 1 & Ensino Superior \\
\hline & Paralisia da Prega Vocal & 1 & Ensino Superior \\
\hline & Baixa Audição & 3 & Ensino Técnico \\
\hline & Transtorno do Déficit de Atenção com Hiperatividade & 2 & Ensino Técnico \\
\hline & Hemimelia Fibular - Membros Inferiores & 1 & Ensino Técnico \\
\hline \multirow{6}{*}{2018} & Baixa Visão & 1 & Ensino Técnico \\
\hline & Baixa Visão & 1 & Ensino Superior \\
\hline & Transtorno do Déficit de Atenção com Hiperatividade & 1 & Ensino Técnico \\
\hline & Surdez & 1 & Ensino Superior \\
\hline & Deficiência física - Membros Superiores & 3 & Ensino Técnico \\
\hline & Paralisia Cerebral & 2 & Ensino Técnico \\
\hline \multirow{6}{*}{2019} & Transtorno do Déficit de Atenção com Hiperatividade & 1 & Ensino Técnico \\
\hline & Surdez & 1 & Ensino Técnico \\
\hline & Surdez & 1 & Ensino Superior \\
\hline & Deficiência física - Membros Superiores & 1 & Ensino Técnico \\
\hline & Paralisia Cerebral & 1 & Ensino Técnico \\
\hline & Déficit Cognitivo & 1 & Ensino Técnico \\
\hline
\end{tabular}

Fonte: Elaborada pelos autores

Cabe ressaltar que em nenhuma das 36 fichas cadastrais de matrícula os alunos informaram serem PcDs com mais de uma deficiência em concomitância. Da totalidade de fichas analisadas, 77,7\% dos alunos efetuaram matrícula na Educação Básica em Cursos Técnicos integrados ou subsequentes ao Ensino Médio. Já quanto ao Ensino Superior, verificou-se um total de $22,3 \%$ com matrícula efetuada. Pontualmente, em relação às deficiências, a análise de dados permitiu a identificação de 16 tipos distintos de deficiências, as quais puderam ser categorizadas, conforme o Decreto $n^{\circ} 5.296$ (BRASIL, 2004), em: Deficiência Física: paralisia cerebral; deficiência física nos membros superiores; Hemimelia Fibular; Neuropatia de Charcot Marie Tooth; paralisia da prega vocal; redução do equilíbrio corpóreo; (b) Deficiência Auditiva: Surdez; baixa audição; (c) Deficiência Visual: baixa visão; (d) Deficiência Intelectual: Déficit Neurológico; Síndrome de Down; (e) Outras Necessidades Educacionais (NE): Transtorno Global de Desenvolvimento (TGD); Transtorno do Déficit de 
Atenção e Hiperatividade (TDAH). Cabe salientar que o NAPNE prevê o atendimento sob responsabilidade do AEE para todos os alunos com NEEs. Durante a análise dos dados também se verificou que há predominância de $27,7 \%$ de alunos com parecer médico de Transtorno de Déficit de Atenção com Hiperatividade (TDAH); 30,5\% de alunos com Deficiência Física; 16,6\% de alunos com Deficiência Visual; 13,8\% com Deficiência Auditiva, 5,5\% Deficiência Intelectual e 30,5\% com outras NEs.

Após o mapeamento dos tipos de deficiência(s), procedeu-se à investigação sobre o tipo de TA disponibilizadas pelo IFRS campus Caxias do Sul para a comunidade acadêmica9 ${ }^{9}$ quando da condução de duas visitas guiadas às dependências da instituição, junto a uma servidora do NAPNE. Diante da catalogação em planilha Microsoft Excel, para fins de registro e posterior agrupamento, a seguir, no Quadro 2, apresenta-se uma lista composta por 41 recursos de TA disponibilizados pelo IFRS campus Caxias do Sul, sendo que esses foram classificados em duas categorias, (a) 15 recursos de TA de auxílio e (b) 26 recursos de TA de software.

Quadro 2 - Mapeamento da Tecnologia Assistiva disponibilizada no IFRS - Caxias do Sul

\begin{tabular}{|c|l|}
\hline $\begin{array}{c}\text { TIPOS DE } \\
\text { RECURSOS }\end{array}$ & \multicolumn{1}{c|}{ DESCRIÇÃO } \\
\hline AUXÍLIO & $\begin{array}{l}\text { 1. Recursos de Leitura - Lupa, Leitor de Arquivos Digitais, Teclado para Deficientes Visuais } \\
\text { (colmeia), Leitor Autônomo com Digitalizador de Voz Integrado; } \\
\text { 2. Recursos de Escrita - Engrossador de Lápis, Reglete; Prancha e Punção, Rotulador Braile; } \\
\text { 3. Mobilidade - Muleta, Bengalas; } \\
\text { 4. Materiais Didáticos - Multiplano, Geoplano, Soroban, Notebook, Xadrez para Deficientes } \\
\text { Visuais; Alfabeto Braile. }\end{array}$ \\
\hline SOFTWAREE & $\begin{array}{l}\text { 1. Leitores de Tela - NVDA; Orca; VoiceOver; TalkBack, DosVox; } \\
\text { 2. Ampliadores de Tela - Lupa do Windows; LentePro; Virtual Magnifying Glass; Lightning 3; } \\
\text { Magnifixer; Zoomlt; } \\
\text { 3. Mudança de Cores - High Contrast; Dark Reader; Dar; Background and Light Text; Blank } \\
\text { Your Monitor + Easy Reading; } \\
\text { Scala; } \\
\text { 5. Alternativas de mouse para computadores - Câmera Mousem e Viacam; HeadDev; } \\
\text { Headmouse; } \\
\text { 6. Alternativas de teclado para computadores - Teclado Virtual do Windows; MouseKey. }\end{array}$ \\
\hline
\end{tabular}

Fonte: Elaborada pelos autores

A oferta de recursos de software e de auxílio de TA foi compreendida como em consonância com o Art. $2^{\circ}$, Lei $\mathrm{n}^{\mathrm{o}} 13.146$, de 6 de julho de 2015, que prevê que as TA podem ser utilizadas, em contextos educacionais, de Educação Básica ou Superior, como recursos

${ }^{9}$ Optou-se pelo termo comunidade acadêmica tento em vista que tanto professores e alunos (usuário final), quanto servidores em geral podem participar dos processos de desenvolvimento, adaptação e utilização de TA que podem mediar a concretização de atividades realizadas no contexto educacional.

RIAEE - Revista Ibero-Americana de Estudos em Educação, Araraquara, v. 16, n. esp. 4, p. 3049-3071, dez. 2021. e-ISSN: 1982-5587 
pedagógicos, ou seja, capazes de mediar os processos de ensino e aprendizagem para PcDs, quando, apropriadamente, utilizadas de acordo com a deficiência do aluno. Tal utilização de uma TA, como mencionado, pode possibilitar a autonomia e a independência da pessoa, bem como para fins de aprendizagem ou consolidação de um conhecimento preexiste do aluno (BRASIL, 2015). Ainda quando às TA, durante as visitas à instituição, constatou-se que os recursos de auxílio são em sua maioria voltados aos alunos cegos e com baixa visão (Lupa, NVDA, DosVox), assim com a alunos com deficiência física (Engrossador de Lápis, MouseKey, Headmouse). No entanto, essa constatação vai de encontro às principais NEEs evidenciadas na Quadro 1, posto que se depreendeu maior incidência de alunos com Transtorno do Déficit de Atenção com Hiperatividade (TDAH).

Referente aos recursos de software verificou-se que esses estão, coerentemente, disponibilizados, de acordo com a demanda de tipos de deficiências dos estudantes. Uma vez se tratando de recursos computacionais, esses são instalados nos computadores que os alunos utilizam. A instituição faz uso de softwares gratuitos, o que permite que inúmeros sejam ofertados, de modo que o aluno possa utilizar aquele que melhor se adapte, conforme sua NEEs. Ainda no que toca às TA, apurou-se a prevalência de TA de software $(63,4 \%)$ em relação às TA de auxílio (36,6\%), o que nos permitiu deduzir que as TA softwares, por serem gratuitas, friendly (amigáveis) e fáceis de adquirir, acabam se tornando mais presentes no campus, até mesmo por estarem disponíveis na atual sociedade da informação (CASTELLS, 1999), da qual os alunos são parte constitutiva. A TA de software abrange, majoritariamente, alunos cegos ou com baixa visão e alunos com deficiências nos membros superiores.

No que diz respeito à segunda etapa de pesquisa, inicialmente, apresenta-se aqui a caracterização dos 08 docentes do IFRS campus Caxias do Sul, enquanto sujeitos de pesquisa, que responderam ao questionário semiestruturado, a fim de que se pudesse constatar representações sociais simbólicas sobre os conceitos de Deficiência e TA, bem como quanto à prática docente com alunos com NEEs. A formação acadêmica inicial dos 08 professores era de Ensino Superior e todos com pós-graduação, sendo que (05) cinco deles possuem doutorado, principalmente voltados ao campo das Engenharias. Todos os professores informaram fazer uso diário da internet, utilizando notebook ou celular do tipo smartphone. Apenas 1 professor relatou fazer uso de computador desktop.

Realizada a caracterização dos docentes e um breve levantamento sobre acesso à internet e uso de recursos computacionais, conduziu-se a análise das narrativas docentes com suporte da técnica de Análise de Conteúdo (BARDIN, 2011), seguindo as etapas previstas na literatura e mencionadas não seção de metodologia. A partir da $\mathrm{AC}$ e seguindo os temas do 
questionário aplicado, (04) eixos foram definidos, os quais foram denominados como (a) Formação Docente - relativo à formação inicial e continuada dos professores na área de Educação Inclusiva; (b) Trabalho Docente, análise dos apontamentos realizados pelos docentes sobre o seu trabalho em relação aos alunos com deficiência e NE; (c) Recursos de $T A$ - aborda o uso de recursos, estratégias ou equipamentos usados pelos professores em sala de aula; e (d) Atendimento - afirmações sobre o acompanhamento dos alunos com deficiência e NE na instituição. A seguir, apresenta-se cada eixo e exemplos de fragmentos discursivos obtidos via questionário, os quais têm por finalidade ilustrar as representações sociais do grupo de professores:

(a) Formação Docente - apenas 2 professores reportaram ter realizado cursos na área da Educação Inclusiva voltada ao uso de TA. Dos 8 entrevistados, 1 informou ter realizado formação, em nível de extensão, promovida pela instituição; 1 informou ter feito curso na área, porém com investimento próprio, e os outros 6 professores relataram nunca ter participado de cursos na área em pauta. Portanto, percebeu-se uma carência acerca da formação docente, aspecto que não faz jus à Lei de Inclusão, Lei nº 13.146 (BRASIL, 2015), que prevê a formação dos professores conforme o artigo 28: "X - adoção de práticas pedagógicas inclusivas pelos programas de formação inicial e continuada de professores e oferta de formação continuada para o atendimento educacional especializado" (BRASIL, 2015, s/p). Assim, pode-se afirmar que há uma lacuna entre teoria e prática, haja vista que existe uma falta de formação dos docentes quanto ao trabalho educacional com alunos com deficiência.

(b) Trabalho Docente (Quadro 03) - a análise das narrativas dos professores sobre o seu trabalho em relação aos alunos com deficiência evidencia haver uma compreensão acerca do conceito de deficiência, conforme previsto por (BRASIL, 2000; 2015; CAT, 2009) e tipos de deficiência, enquanto construto de representações sociais simbólicas (BRASIL, 2004), tendo em vista que a maioria desses nunca realizou formação nesta área de conhecimento.

Quadro 3 - Fragmentos das narrativas dos professores

\begin{tabular}{|c|l|}
\hline \multicolumn{2}{|c|}{ TRABALHO DOCENTE } \\
\hline PARTICIPANTE & \multicolumn{1}{c|}{ NARRATIVA } \\
\hline P1 & $\begin{array}{l}\text { "Ausência de (ou anormalidade em) alguma função do corpo ou mente por um longo } \\
\text { prazo." } \\
\text { "Físicas, sensoriais e intelectuais. A dificuldade no trabalho em sala de aula depende } \\
\text { também de fatores externos a própria deficiência do estudante, mas, em geral, na área em } \\
\text { que atuo, deficiência visual e intelectual são as que tenho mais dificuldade de manejo." }\end{array}$ \\
\hline P3 & $\begin{array}{l}\text { "Uma característica física ou cognitiva que faz com que determinada pessoa apresente uma } \\
\text { ou mais dificuldades para realiza certas atividades práticas ou teóricas quando comparada a } \\
\text { um padrão pré-estabelecido." }\end{array}$ \\
\hline
\end{tabular}

RIAEE - Revista Ibero-Americana de Estudos em Educação, Araraquara, v. 16, n. esp. 4, p. 3049-3071, dez. 2021. e-ISSN: 1982-5587 


\begin{tabular}{|c|l|}
\hline \multirow{3}{*}{$\mathbf{P 8}$} & $\begin{array}{l}\text { "Acredito que eu conheça algumas: deficiência auditiva, deficiência visual, deficiência } \\
\text { intelectual, TDAH, deficiência física. Penso que há maior dificuldade em casos de } \\
\text { deficiência visual e deficiência intelectual." }\end{array}$ \\
\hline "Uma condição específica que pode ou não trazer restrições de acesso a algumas pessoas. \\
$\begin{array}{l}\text { E essas restrições devem-se à maneira como o mundo e a sociedade estão organizados, } \\
\text { privilegiando as pessoas "sem deficiências". } \\
\text { "Paralisia cerebral, síndrome de Down, cegueira e surdez." }\end{array}$ \\
\hline
\end{tabular}

Fonte: Elaborada pelos autores

As narrativas, ainda enquanto representações sociais simbólicas para aquilo que pouco ou quase nada se obteve através de formação científica, revelam uma perspectiva do conceito de deficiência pautado na perspectiva do Modelo Médico (DINIZ; BARBOSA; SANTOS, 2009), focando em um corpo com impedimentos, e não por um viés do Modelo Pós-Social (DINIZ; BARBOSA; SANTOS, 2009; BISOL; PEGORINI; VALENTINI, 2017). Este trata sobre a inclusão de pessoas com deficiências, principalmente, relativo à inclusão escolar, assegurando o atendimento pedagógico, recursos específicos e a inclusão, a fim de gerir os cuidados necessários para que o aluno com deficiência tenha acesso ao ensino.

Ainda na perspectiva da deficiência como impedimento e fator de dificuldade, os professores enfatizam seus problemas para trabalhar com alunos com certos tipos de deficiências e NEEs, aspecto que corrobora uma representação simbólica do conceito de deficiência consolidado ao Modelo Médico (DINIZ, 2009), em que a deficiência por si só é tomada como restritiva, sem que se leve em conta os aspectos contextuais do cenário educacional como um todo. Além disso, os professores elencaram uma gama de tipos de deficiências e NEEs (deficiência física, visual, sensoriais, surdez, baixa visão, paralisia cerebral, TDAH, dificuldade de mobilidade, autismo, mobilidade reduzida, síndrome de Down e déficit cognitivo), o que aponta que apesar da lacuna quanto à formação científica no campo da Deficiência, a prática profissional leva-os à construção de conhecimentos coconstruídos no âmago do fazer e ser docente. Esse conhecimento que emerge da prática social e profissional, no entanto, permite com que se infira que os professores têm conhecimento sobre as deficiências dos alunos na instituição (Quadro 1). Na tentativa de contornar a ausência de formação profissional e docente, (06) seis professores informaram que realizam pesquisa na internet sobre deficiência, recursos e metodologias de ensino e aprendizagem para auxiliar no desenvolvimento do conteúdo e para compreender a necessidade educacional do aluno. Todos os professores ${ }^{10}$ receberam da Instituição um notebook para fins de trabalho com recursos para as disciplinas. Quando questionados, 06 professores relataram que usam os dispositivos para pesquisar e organizar materiais para os alunos com deficiência e NEs. Dos

${ }^{10}$ Neste caso considerou-se os professores do quadro de efetivos da instituição.

RIAEE - Revista Ibero-Americana de Estudos em Educação, Araraquara, v. 16, n. esp. 4, p. 3049-3071, dez. 2021. e-ISSN: $1982-5587$ 
(08) oito professores entrevistados, (07) sete reportaram ter conhecimento sobre o NAPNE e apenas (01) um disse não ter proximidade com o núcleo.

(c) Recursos de TA (Quadro 4) - relativo ao uso de recursos de TA, estratégias ou equipamentos usados pelos professores, a análise das narrativas possibilitou identificar o que os professores compreendem sobre o conceito de TA: o abordam como um recurso assistencialista (DINIZ; BARBOSA; SANTOS, 2009; MARTÍN; CASTILLO, 2010), como pode-se observar nos fragmentos discursivos abaixo.

Quadro 4 - Fragmentos das narrativas dos professores

\begin{tabular}{|c|c|}
\hline \multicolumn{2}{|r|}{ RECURSOS DE TA } \\
\hline PARTICIPANTE & NARRATTIVA \\
\hline P4 & $\begin{array}{l}\text { "Compreendo como aqueles meios (vídeos, legendas, jogos...) que fornecem uma atenção } \\
\text { especial ao estudante facilitando o aprendizado dele... e melhores condições didáticas para } \\
\text { o professor trabalhar com o aluno que tenha necessidade especial." }\end{array}$ \\
\hline P5 & $\begin{array}{l}\text { São recursos (dos mais variados tipos, tanto mecânicos, materiais concretos, lúdicos e } \\
\text { digitais) que auxiliam alunos com NEE a terem maior autonomia, possibilitando um grau } \\
\text { maior de interação com o professor, com a disciplina e muitas vezes com a própria turma. }\end{array}$ \\
\hline P8 & $\begin{array}{l}\text { "São recursos (tecnológicos ou não) que podem ser usados para dar equidade de acesso às } \\
\text { pessoas que têm algum tipo de restrição em virtude de alguma condição física (ou } \\
\text { mental)." }\end{array}$ \\
\hline
\end{tabular}

Fonte: Elaborada pelos autores

Conforme o referencial adotado, os docentes apropriam-se de uma construção simbólica, logo, representações sociais do conceito de TA de forma divergente à prevista na literatura da área, ou seja, diferente do que definem os documentos oficiais (BRASIL, 2000; 2015), CAT (2009), Cook e Hussey (1995) e Bersch (2017), quanto ao entendimento de que as TA visam promover autonomia, independência, qualidade de vida e inclusão da pessoa com deficiência. Há uma crença atribuída pelos docentes em caráter de apoio e não pelo verdadeiro viés e finalidade de utilização de TA no campo educacional. Neste horizonte, é possível afirmar que os professores se mantiveram, linearmente, à sombra do Modelo Médico (DINIZ, 2009), assim como observado com o conceito de deficiência, pois 6 docentes abordam as TA como instrumento de assistência. Apenas o participante P5 fez alusão ao conceito de TA de forma mais elaborada, considerando a bibliografia citada neste estudo. Nenhuma das respostas analisadas considerou a TA como um instrumento de mediação para a aprendizagem, conforme a visão vigotskiana (VIGOTSKI, 1991), mas sim com uma visão de assistir/auxiliar o aluno com deficiência. É importante pontuar que apenas (02) dois professores disseram fazer uso de TA em suas aulas. Contudo, três participantes relataram fazer uso recursos de TA; quando questionados informaram: mouse adaptado; teclado virtual; aumento de tamanho de fonte; tablet com programas específicos; fichas com palavras e 
imagens; projetor; softwares (não especificado); intérprete de libras; gravador de voz, metodologias adaptadas para cada deficiência ou NE. A análise das narrativas evidenciou que os professores possuem um conhecimento moderado sobre o conceito de TA, mostrando que metade dos docentes associa a TA com o termo de assistência ou atendimento. É provável que a representação do conceito ainda esteja sendo construída pelos professores, exatamente como um construto social, localmente constituído por representações sociais, mas que, no contexto de pesquisa deste estudo, devem ser elaboradas com base na TRS.

(d) Atendimento a alunos com NEEs (Quadro 5) - concernente às narrativas sobre o atendimento a alunos com deficiência e NEs na instituição, os professores informaram solicitar realizar o AEE ou solicitar acompanhamento de um técnico de AEE. Dos (08) oitos professores, (04) quatro relataram que realizam atendimento ou solicitaram ajuda da técnica de AEE, os outros (04) quatro responderam não fazer ou não ter havido necessidade ou oportunidade de realizar atendimento aos alunos com deficiência.

Quadro 5 - Fragmentos das narrativas dos professores

\begin{tabular}{|c|l|}
\hline \multicolumn{2}{|c|}{ ATENDIMENTO A ALUNOS COM NEEs } \\
\hline PARTICIPANTE & \multicolumn{1}{c|}{ NARRATTIVA } \\
\hline P3 & $\begin{array}{l}\text { "Até o momento não necessitei, mas penso que dependendo da deficiência é indispensável } \\
\text { que o aluno seja acompanhado por um profissional específico durante as aulas." }\end{array}$ \\
\hline P4 & $\begin{array}{l}\text { "Sim, pois é por meio da Técnica de AEE que consigo entender melhor os desafios do } \\
\text { estudante é a partir daí fornecer melhores condições de ensino." }\end{array}$ \\
\hline P7 & $\begin{array}{l}\text { "Tenho atendido os alunos, mas em alguns casos têm sido extremamente difíceis avançar } \\
\text { com a turma e ter um progresso com o aluno." }\end{array}$ \\
\hline
\end{tabular}

Fonte: Elaborada pelos autores

Com a abordagem das narrativas apresentadas, percebe-se que os docentes compreendem a importância do AEE, mesmo com dificuldades, como relatado pelo participante P7. Conforme o IFRS (2012) e a Lei n ${ }^{0} 13.146$ (BRASIL, 2015), a instituição tem promovido o AEE através de técnico de AEE e também pelos professores, mesmo que esses apresentem dificuldades e/ou ainda não tiveram a oportunidade de trabalhar com alunos com deficiência ou NEs.

\section{Considerações finais}

Este estudo mapeou os tipos de deficiências dos alunos do IFRS campus Caxias do Sul e os tipos de TA (auxílio e software) disponibilizadas pela instituição, assim como entrevistou professores, com vista a analisar, por meio de suas narrativas, representações sociais acerca dos conceitos de deficiência e uso de TA em suas práticas com alunos com deficiência e NE. 
Identificou-se a predominância da NE do tipo TDAH e deficiência física, e um maior quantitativo de TA voltadas aos alunos com baixa visão, aspecto que se mostrou deficitário, haja vista que há uma demanda mais expressiva por TA para alunos com TDAH e deficiência física. Quanto aos alunos com deficiências declaradas, apurou-se maior número a nível de Ensino Médio Técnico (28 alunos) do que a nível de Ensino Superior (08 alunos), aspecto que deixa nítida a dificuldade de acesso ao Ensino Superior por PcDs, neste caso, alunos que precisam de AEE. Outro aspecto que emergiu desta pesquisa foi quanto à maior expressividade de oferta de TA de software, o que se justifica devido à atual sociedade da informação em que estamos inseridos. Um aspecto importante sobre a oferta de TA software disponibilizadas pelo IFRS é que por serem, em geral, gratuitas, essas podem ser utilizadas pelos alunos com NEEs em outros espaços, para além do ambiente educacional. Isso permite que os alunos possam se familiarizar com os recursos tecnológicos até mesmo para além de suas atividades escolares, descobrindo funções outras para as TA.

No que se refere às entrevistas, constatou-se a falta de formação docente voltada à área da Educação Inclusiva, sobre deficiências e TA como uma lacuna entre teoria e prática, isso porque toda a literatura e a legislação preveem a formação do profissional da educação para a condução de boas práticas nos processos de ensino e aprendizagem de alunos com deficiência, seja em sala de aula ou no AEE. As narrativas revelaram não apenas a falta de formação, mas as consequências dessa, posto que a maioria dos professores reportaram dificuldades em trabalhar com alunos com deficiência, seja por não compreender as necessidades educacionais desses ou o tipo de TA a ser adotada de modo coerente. Constatou-se que os professores apresentaram representações sociais simbólicas para o conceito de deficiência sob a perspectiva do Modelo Médico, excluindo o contexto do Modelo Pós-Social, por vezes por pouco conhecerem essa perspectiva do Modelo Pós-Social. Talvez esse seja um aspecto a considerar na formação continuada de professores. Por fim, ficou evidente que os professores têm conhecimento sobre os recursos de TA e as deficiências(s) dos alunos, porém não sabem como utilizá-las na promoção da autonomia e da independência do estudante com deficiência ou NEE no ambiente escolar, sem percebê-las como instrumentos mediadores para a construção do conhecimento. 


\section{REFERÊNCIAS}

BARDIN, L. Análise de Conteúdo. São Paulo: Edições 70. 2011.

BISOL, C. A.; PEGORINI, N. N.; VALENTINI, C. B. Pensar a deficiência a partir dos modelos médico, social e pós-social. Cadernos de Pesquisa, São Luís, v. 24, n. 1, p.87-100, jan. 2017. Trimestral. Disponível em: https://rb.gy/ythu45. Acesso em: 04 mar. 2020.

BISOL, C. A. et al. Desafios para a inclusão de estudantes com deficiência física: uma revisão de literatura. Conjectura Filosofia e Educação, v. 23, n. 3, p. 601-619, set. 2018.

Universidade Caxias do Sul. Disponível em: https://rb.gy/g2cqbs. Acesso em: 29 fev. 2020.

BRASIL. Constituição (2000). Lei n. 10.098, de 19 de dezembro de 2000. Normas Gerais e Critérios Básicos Para A Promoção da Acessibilidade das Pessoas Portadoras de Deficiência Ou Com Mobilidade Reduzida, e Dá Outras Providências. Brasília, DF, 19 dez. 2000.

Disponível em: https://rb.gy/6jcjxe. Acesso em: 04 mar. 2020.

BRASIL. Palácio do Planalto. Decreto n. 5.296, de 2 de dezembro de 2004. Regulamenta as Leis $\mathrm{n}^{\mathrm{o}} 10.048$, de 8 de novembro de 2000 , que dá prioridade de atendimento às pessoas que especifica, e no 10.098, de 19 de dezembro de 2000. Brasília, 2004. Disponível em: https://rb.gy/x8pwvk. Acesso em: 06 jul. 2019

BRASIL. Cartilha do Censo 2010. Pessoas com Deficiência / Luiza Maria Borges Oliveira; Brasília, DF: SDH-PR/SNPD, 2010, 32 p. Disponível em: https://rb.gy/qwrczp. Acesso em 04 mar. 2020

BRASIL. Constituição (2015). Lei n. 13.146, de 06 de julho de 2015. Lei Brasileira de Inclusão da Pessoa Com Deficiência (estatuto da Pessoa Com Deficiência). Brasília, DF, 06 jul. 2015. Disponível em: https://rb.gy/vglkkj. Acesso em: 04 mar. 2020.

BRASIL. Constituição (2016). Lei n. 13.409, de 28 de dezembro de 2016. Reserva de Vagas Para Pessoas Com Deficiência nos Cursos Técnico de Nível Médio e Superior das Instituições Federais de Ensino. Brasília, DF, 28 dez. 2016. Disponível em: https://rb.gy/ekpok6. Acesso em: 02 jul. 2019.

BERSCH, R. Introdução a Tecnologia Assistiva. 2017. Disponível em: https://rb.gy/1bwt1h. Acesso em: 15 fev. 2020.

BARWALDT, R.; SANTAROSA, L. M. C.; PASSERINO, L. M. Uma ferramenta de autoria síncrona acessível para cegos: um estudo de caso no curso PROINESP. Renote, Porto Alegre, v. 6, n. 1, p.1-10, dez. 2008. Disponível em: https://rb.gy/mqp4gp. Acesso em: 29 fev. 2020.

CARVALHO, R. E. Educação Inclusiva: com os pingos nos "is". 11. ed. Porto Alegre: Mediação, 2016. 174 p.

CASTELLS, M. A sociedade em rede. São Paulo: Paz e Terra, 1999.

CAMPOS, P. H. F. O estudo da ancoragem das Representações Sociais e o campo da Educação. Revista de Educação Pública, Cuiabá, v. 26, n. 63, p.775-797, set. 2017. 
CAT, Subsecretaria Nacional de Promoção dos Direitos da Pessoa com Deficiência. Comitê de Ajudas Técnicas. Tecnologia Assistiva. Brasília, DF: CORDE, 2009.

CORRÊA, Y.; GOMES, R. P.; RIBEIRO, V. G. Aplicativos de Tradução Português-Libras na Educação Bilíngue de Surdos: tradução por meio de sinais ou datilologia? Renote, v. 16, n. 1, p.1-10, 21 ago. 2018. Universidade Federal do Rio Grande do Sul. Disponível em: https://rb.gy/ctfy15. Acesso em: 15 fev. 2020.

CORRÊA, Y. et al. Tecnologia Assistiva: a inserção de aplicativos de tradução na promoção de uma melhor comunicação entre surdos e ouvintes. Informática na Educação: Teoria \& Prática, Porto Alegre, v. 1, n. 12, p.1-10, jul. 2014.

COOK, A. M.; HUSSEY, S. M. Assistive Technologies: Principles and Practices. St. Louis, Missouri. Mosby: Year Book, Inc., 1995.

DINIZ, D.; BARBOSA, L.; SANTOS, W. R. Deficiência, direitos humanos e justiça. Sur. Revista Internacional de Direitos Humanos, v. 6, n. 11, p. 64-77, dez. 2009. Disponível em: https://rb.gy/cmshoz. Acesso em: 05 maio 2019.

FERRADA, R. B. H.; SANTAROSA, L. M. C. Tecnologia assistiva como apoio à inclusão digital de pessoas com deficiência física. Porto Alegre, dez. 2009. p. 1-8. Disponível em: https://rb.gy/pgnovp. Acesso em: 29 fev. 2020.

FERREIRA, M. A. V. Discapacidad, globalidad y educación: ¿una nueva "política del cuerpo"? Revista Latinoamericana de Estudios Sobre Cuerpos, Emociones y Sociedad, Córdoba, v. 6, n. 3, p. 6-19, ago. 2011. Disponível em: https://rb.gy/4k7d2j. Acesso em: 05 maio 2019

IFRS. Projeto Pedagógico Institucional do IFRS. Bento Gonçalves, 2012. 67 p. Disponível em: https://rb.gy/2ktof9. Acesso em: 03 mar. 2020.

JODELET, D. Representações Sociais: um domínio em expansão. In: JODELET, D. As representações sociais. Rio de Janeiro: EDUERJ, 2001. p. 17-44.

JODELET, D. Representações sociais: um domínio em expansão. In: JODELET, D. (org.). As Representações sociais. Rio de Janeiro: Eduerj, 2002. p. 17-44.

JOVCHELOVITCH, S. Os Contextos do saber: representações, comunidade e cultura. Petrópolis, RJ: Vozes, 2008.

MARTÍN, M. T.; CASTILLO, F. G. Cuerpos, capacidades, exigencias funcionales... y otros lechos de Procusto. Política y Sociedad, Madrid, v. 47, n. 1, p. 67-83, mar. 2010. Disponível em: https://rb.gy/4aigrv. Acesso em: 06 maio 2019.

MAZZOTTI, A. J. A. A abordagem estrutural das representações sociais. Psicologia da Educação, São Paulo, n. 14/15, p. 17-37, 2002.

MOSCOVICI, S. A Representações Sociais da psicanálise. Rio de Janeiro: Zahar, 1978. 
SAMPIERI, R. H.; COLLADO, C. F.; LUCIO, M. P. B. Metodologia de pesquisa. 5. ed. Porto Alegre, RS: Penso, 2013. 624 p.

SONZA, A. P.; SALTON, B. P.; STRAPAZZON, J. A. (org.). O Uso Pedagógico dos Recursos de Tecnologia Assistiva. Bento Gonçalves, RS: Companhia Rio-grandense de Artes Gráficas, 2015. 224 p.

SONZA, A. P. et al. (org.). Acessibilidade e tecnologia assistiva: pensando a inclusão sociodigital de pessoas com necessidades especiais. Bento Gonçalves, RS, 2013. 370 p.

SONZA, A. P.; SANTAROSA L. M. C. Ambientes digitais virtuais: acessibilidade aos deficientes visuais. In: CICLO DE PALESTRAS SOBRE NOVAS TECNOLOGIAS NA EDUCAÇÃO, 1., 2003, Porto Alegre. Anais [...]. Porto Alegre, RS: CINTED-UFRGS, 2003. p. $1-11$.

SOUSA, C. P. Estudos de representações sociais em educação. Psicologia da Educação, São Paulo, n. 14/15, p. 285-323, dez. 2002.

VALA, J. Representações sociais e psicologia social do conhecimento quotidiano. In: VALA, J.; MONTEIRO, M. B. (org.). Psicologia social. Lisboa: Fundação Calouste Gulbenkian, 2004. p. 457-501.

VIGOTSKI, L. S. A Formação Social da Mente. 4. ed. São Paulo: Martins Fontes, 1991. $168 \mathrm{p}$.

WARSCHAUER, M. Tecnologia e inclusão social: a exclusão digital em debate. São Paulo: Senac, 2006. 319 p.

\section{Como referenciar este artigo}

MORO, T. B.; CORREA, Y.; MARCOLLA, V.; WELTER, C. B. Representações Sociais Docentes acerca dos conceitos de Deficiência e Tecnologia Assistiva. Revista IberoAmericana de Estudos em Educação, Araraquara, v. 16, n. esp. 4, p. 3049-3071, dez. 2021. e-ISSN: 1982-5587. DOI: https://doi.org/10.21723/riaee.v16iesp.4.16067

Submetido em: 19/08/2021

Revisões requeridas em: 30/10/2021

Aprovado em: 10/12/2021

Publicado em: 30/12/2021 